\title{
Selective Adsorption of Cobalt In Aqueous Solution Using Chemically Modified Activated Carbon.
}

\author{
Jitendra K. Gunjate* \\ Department of Chemistry, SSES Amt's Science College, Congress Nagar, Nagpur, India
}

\begin{abstract}
In this study, removal of cobalt from aqueous solution by adsorption was investigated. For this purpose high grade $\mathrm{CoSO}_{4} \cdot \mathrm{H}_{2} \mathrm{O}$ was used as heavy metal samples. The performance of granular activated carbon in presence with 1,2- Dihydroxybenzene for adsorption of cobalt ions from aqueous solution at temperature $25+I^{\circ} \mathrm{C}$ was studied. The experimental data showed good correlation with Langmuir and Freundlich isotherm model.
\end{abstract}

Keywords: Adsorption, Cobalt, Granular Activated Carbon (GAC), Filtrasorb 100 (F-100), Filtrasorb 816 (F816), 1,2 Dihydroxybenzene.

\section{Introduction}

Heavy metal water pollution has become a growing ecological crisis and hence matter of great concern for researcher and scientist. Industrial wastewater is considered to be the main source of Cobalt impurities. Unlike organic pollutants, heavy metals are non-biodegradable, toxic and accumulate in living organisms $[1,2]$. Some metals such as $\mathrm{Co}, \mathrm{Cd}, \mathrm{Hg}, \mathrm{Ag}$ and $\mathrm{Pb}$ can become extremely toxic to living beings, others such as $\mathrm{Cu}, \mathrm{Zn}$, $\mathrm{Mn}, \mathrm{Fe}, \mathrm{Ni}$ and $\mathrm{Cr}$ though essential for plant and animals, when present in excess concentrations and above certain limits, can be very harmful to living organisms. Stringent environmental regulation attracts the attention of chemists and environmental engineers for its control.

Cobalt is beneficial for humans because it is a part of vitamin $\mathrm{B}_{12}$, which is essential for human health. When plants grow on contaminated soils they will accumulate very small particles of cobalt, especially in the parts of the plant we eat, such as fruits and seeds. Soil near mining may contain very high amounts of cobalt, so that the uptake by humans through eating plants can cause health effects. However too high concentration of cobalt may damage human health causing asthma, pneumonia, vomiting, nausea, vision problem, heart problem, thyroid damage etc [3,4]. Cobalt is present in most of the waste to some extent. Hence in this laboratory, work was initiated in trying to scavenge this metal from aqueous solutions so that it could be used purposely later on. Very limited information is available on the use of ligands and their role in scavenging cobalt from solution.

Exposure to these contaminants present even in low concentrations in the environment can prove to be harmful to the human health. The excessive release of heavy metals into the environment is a major concern worldwide. Electroplating, mining operations, tanneries, smelting alloy industries and storage batteries industries etc. have greatly enhanced the concentration of heavy metals in industrial wastewater and these metal ions do not degrade into harmless end products. Industrial effluent constitutes the major source of various kinds of metal pollution in natural water. The hazardous heavy metals include $\mathrm{Cd}, \mathrm{Zn}, \mathrm{Pb}, \mathrm{Ni}$, Co etc.

The removal of heavy metals from contaminated water bodies has been attempted by several scientists employing wide variety of techniques including chemical precipitation, ion exchange, electro flotation, coagulation, solvent extraction, membrane filtration, reverse osmosis etc. There are several methods used for water treatment. All these methods are generally expensive. For this reason there is a need for developing economic and eco-friendly methods for waste minimization and fine tuning of wastewater. Hence it is necessary to develop easily available, inexpensive and equally effective alternatives for waste water treatment. The adsorption has been shown to be economically feasible and inexpensive alternative for removing metals from waste water [5-13].

\section{Materials And Methods}

The granular activated carbon F-100 and F-816 gifted by M/s Calgon Carbon Corporation Ltd Pittusberg, USA were used as adsorbents to adsorb $\mathrm{Co}^{2+}$ ions from aqueous solution. These GACs were first subjected to size fractionation to get the appropriate size carbon particles. Both carbons were sieved using a sieve shaker wherein the size corresponding to mesh size 16 x 25 (M/s Jayant Test Sieves, Mumbai) were collected for use. The sieved GAC particles were thoroughly washed with hot distilled water to remove organic matter and then dried in an oven at a temperature of $110^{\circ} \mathrm{C}$ for 15 hours and later cooled in a desiccators containing anhydrous $\mathrm{CaCl}_{2}$ to ensure complete removal of moisture from the pores of carbon. A stock solution of Cobalt ions was obtained by dissolving calculated amount of $\mathrm{CoSO}_{4}$ (E. Merck) in distilled water. A series of solutions of known concentration of cobalt ions were prepared. Spectrophotometrically, Beer's law calibration 
curve was established for $\mathrm{Co}^{2+}$ using Nitroso-R-Salt method, to estimate residual concentration of cobalt ions [14].

All reagents used in the present study were of analytical grade. A sample of 1,2 Dihydroxybennzene (S.D.F. Chem Ltd)was purified and recrystallized prior to use by standard method. The experimental melting point of 1,2-Dihydroxybezene was found to be $102^{\circ} \mathrm{C}$ and compared with literature value. The sample was also characterized through determination of molecular weight by the technique of $\mathrm{pH}$ titration against standard alkali. To evaluate the adsorption equilibrium data, experiments were carried out in batch system. The adsorption isotherm of Cobalt ion on selected grades of carbon modified with as 1,2 Dihydroxybenzene were carried out . For this $0.5 \mathrm{~g}$ of the GAC and $200 \mathrm{ml}$ of the ligand solution of a specified concentration was taken in reagent bottle of $300 \mathrm{ml}$ capacity and it was then shaken for about five hours using Teflon bladed stirrer at about 500 rpm. The solution was then drained off and the carbon particles were washed thoroughly with distilled water. This loaded carbon was then transferred to same reagent bottle and then $200 \mathrm{ml}$ of Cobalt solution at a $\mathrm{pH}=5$ were added to it. The contents were agitated for 5 hours in a thermostat at a constant temperature of $25 \pm 1^{0} \mathrm{C}$. The initial and final concentrations of the Cobalt ion in $\mathrm{mg} / \mathrm{L}$ was then determined by measuring absorbance spectrophotometrically using Chemito spectrascan UV 2700 Double beam UV Visible spectrophotometer at 425 nm wavelength. The experiments were repeated to ensure reproducible results.

\section{Characterisation of Adsorbent}

The activated carbons namely F-100 and F-816 were characterised by FT-IR and scanning electron microscopy for removal of $\mathrm{co}^{2+}$ ions. Fig. 1 and 2 shows the peaks of FT-IR spectrum of different functional groups according to their corresponding wave numbers. The obtained data of FT-IR analysis indicated that GAC F-100 and F-816 surface contaions $-\mathrm{COOH},-\mathrm{OH}$ groups which increases the metal adsorption.

The SEM images (Fig 3-4) detected the structure of the GAC surface porous in nature which provide large surface area responsible for high uptake of metal ions.

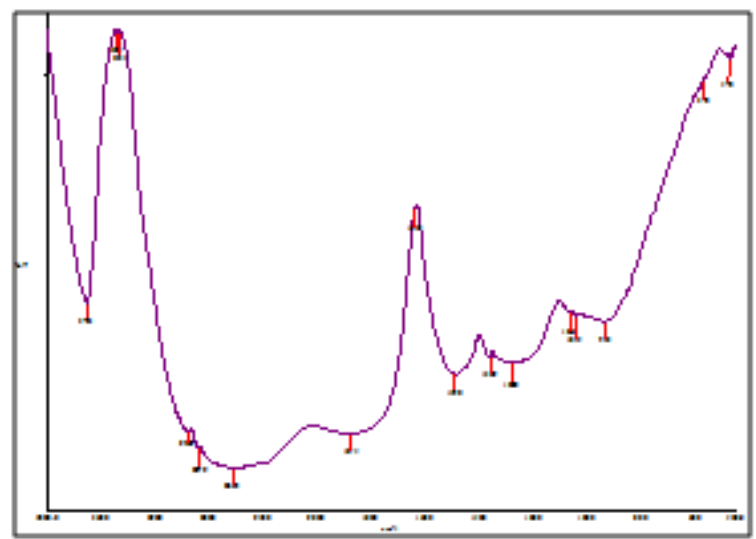

Fig. 1. : FT-IR of F 100 Granular Activated Carbon

\section{SEM Images}

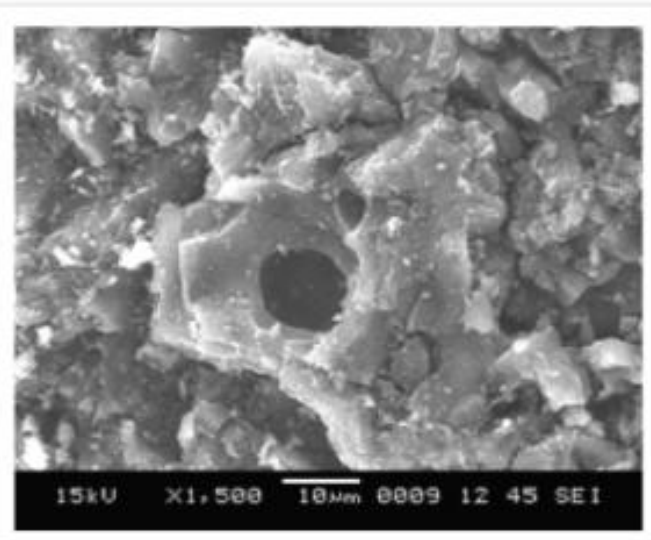

Fig 3: Scanning Electron Micrograph of F 100 Granular Activated Carbon

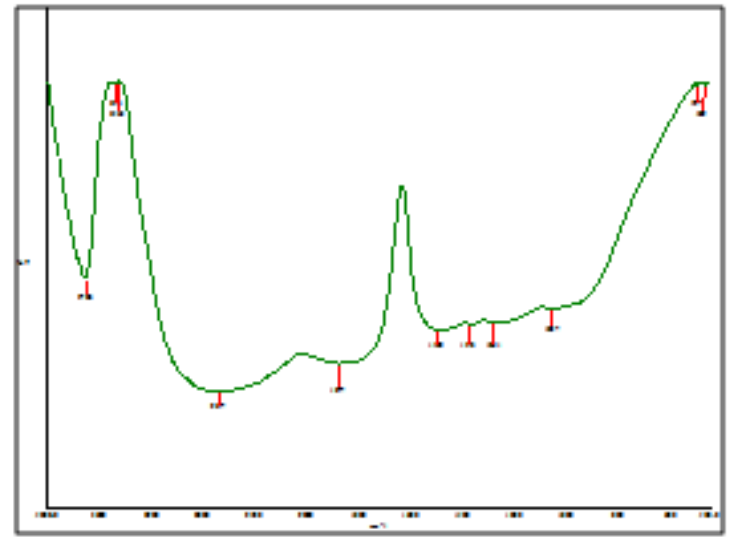

Fig. 2. : FT-IR of F 816 Granular Activated Carbon

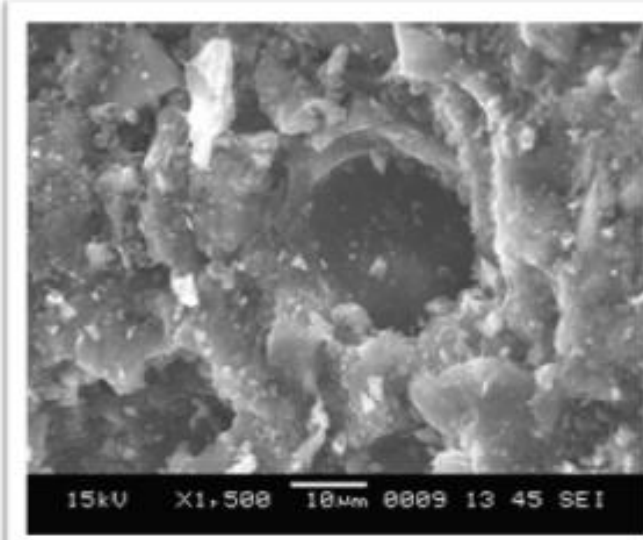

Fig 4: Scanning Electron Micrograph of F 816 Granular Activated Carbon 


\section{Results And Discussion}

The experimental data of adsorption of $\mathrm{Co}^{2+}$ on GAC were analyzed in the light of Langmuir and Freundlich isotherms. The adsorption isotherm describes the relationship between the liquid phase concentration and surface concentration of adsorbate at equilibrium, the amount of Cobalt on the ligand loaded GAC was determined using the equation

$$
\mathrm{q}_{\mathrm{e}}=\left(\mathrm{C}_{0}-\mathrm{Ce}\right) \times \frac{\mathrm{V}}{\mathrm{W}}
$$

Where,

$\mathrm{q}_{\mathrm{e}}=$ Concentration of Cobalt ion on the ligand loaded GAC in $\mathrm{mg} / \mathrm{millimoles}$ of ligand,

$\mathrm{C}_{\mathrm{o}}=$ Initial concentration of Cobalt ion in solution in $\mathrm{mg} / \mathrm{L}$,

$\mathrm{C}_{\mathrm{e}}=$ Final concentration of Cobalt ion in solution in $\mathrm{mg} / \mathrm{L}$,

$\mathrm{V}=$ Volume of solution in liters,

$\mathrm{W}=$ Millimoles of the ligand actually present on $\operatorname{GAC}(0.5 \mathrm{~g})$.

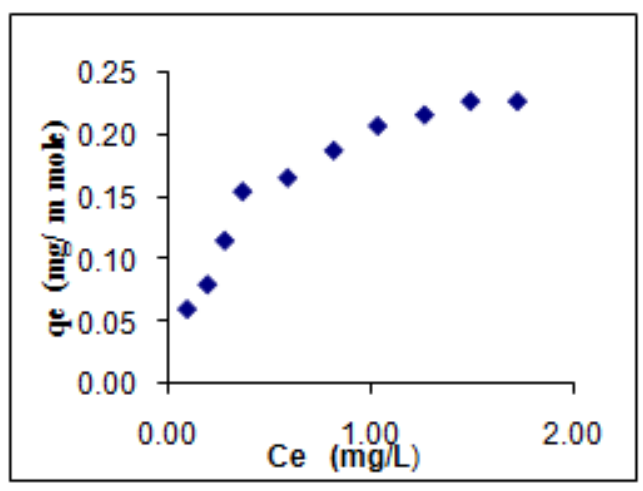

Fig.1. Adsorption isotherm

System: F-100-1,2- Dihydroxybenzene - $\mathrm{Co}^{2+}$

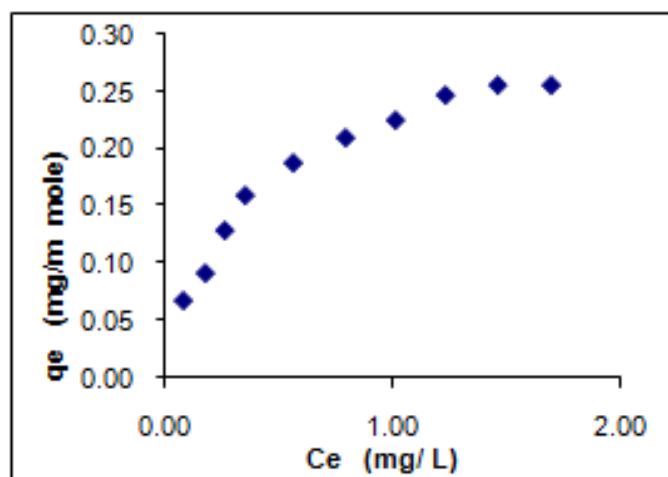

Fig.2.Adsorption isotherm System: F-816-1,2- Dihydroxybenzene - $\mathrm{Co}^{2+}$

The adsorption isotherms of ligand loaded F-100 and F-816 GAC obtained by plotting $\mathrm{q}_{\mathrm{e}}$ versus $\mathrm{C}_{\mathrm{e}}$ and shown in Fig. 1 and Fig. 2. Using values of $\mathrm{q}_{\mathrm{e}}$ versus $\mathrm{C}_{\mathrm{e}}$, the Langmuir equation could be expressed as

$$
\mathrm{q}_{\mathrm{e}}=\mathrm{Q}^{0} \mathrm{~b} \times \frac{\mathrm{C}_{\mathrm{e}}}{\left(1+\mathrm{bC}_{\mathrm{e}}\right)}
$$

Where,

$\mathrm{Q}^{\mathrm{o}}=$ amount adsorbed per unit weight of the adsorbent forming a complex monolayer on the adsorbent surface.

$\mathrm{b}=$ Langmuir constant.

Rearranging equation (3)

$$
\frac{1}{\mathrm{q}_{\mathrm{e}}}=\frac{1}{\mathrm{Q}^{0} \mathrm{~b}} \times \frac{1}{\mathrm{C}_{\mathrm{e}}}+\frac{1}{\mathrm{Q}^{0}}
$$

A plot of $1 / \mathrm{q}_{\mathrm{e}}$ versus $1 / \mathrm{Ce}$ was found to be fairly linear. Similarly, the Freundlich equation used was

$$
\mathrm{qe}_{\mathrm{e}}=\mathrm{k} \cdot \mathrm{C}_{\mathrm{e}}^{1 / \mathrm{h}}
$$

Where, $\mathrm{k}$ and $1 / \mathrm{n}$ are constants determine experimentally. Using equation (4)

$\log q_{e}=\log k+\frac{1}{n} \log C_{e}$

A plot of $\log \mathrm{q}_{\mathrm{e}}$ versus $\log \mathrm{C}_{\mathrm{e}}$ fairly showing validity of Freundlich equation over a range of concentrations.

Fig.3 to 6 illustrates the plot of Langmuir and Freundlich isotherms for F-100 and F-816. The plots of 1/q versus $1 / C_{e}$ were found to be linear indicating the applicability of Langmuir model. The parameters $Q^{\circ}$ and $b$ are Langmuir constants relating to the sorption capacity and adsorption energy respectively were determined. 


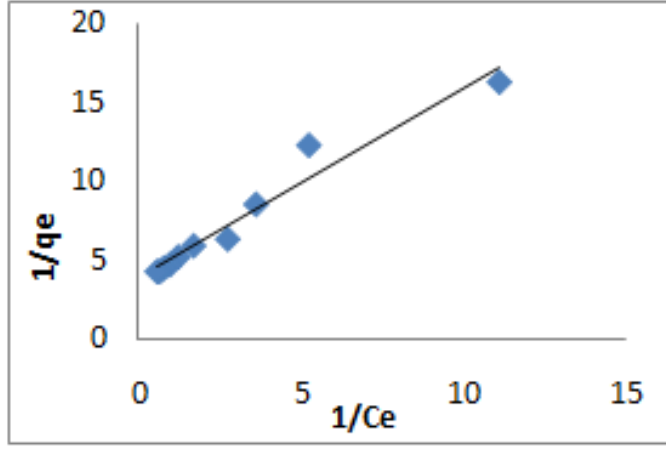

Fig.3 .Langmuir adsorption isotherm System: F-100 -1,2 Dihydroxybenzene $-\mathrm{Co}^{2+}$

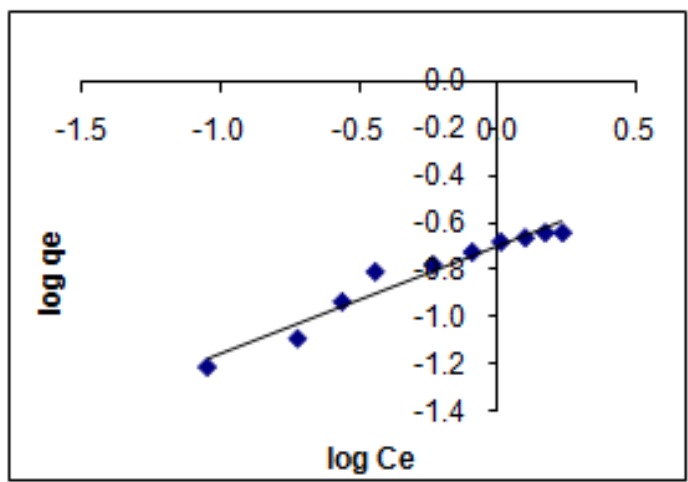

Fig.5.Freundlich adsorption isotherm System: F-100-1,2 Dihydroxybenzene- $\mathrm{Co}^{2+}$.

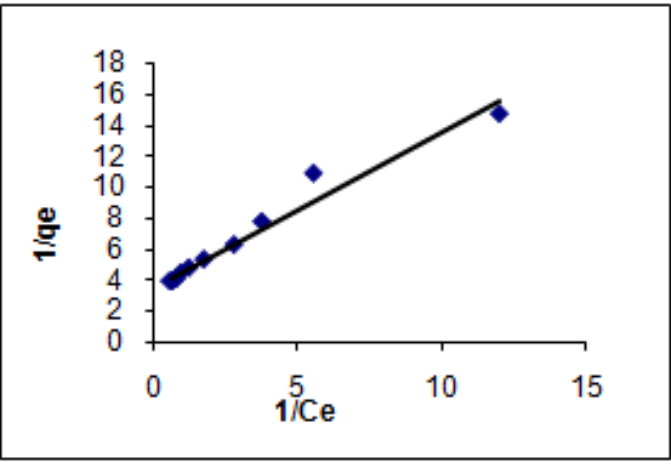

Fig. 4 .Langmuir adsorption isotherm System: F-816-1,2 Dihydroxybenzene $-\mathrm{Co}^{2+}$

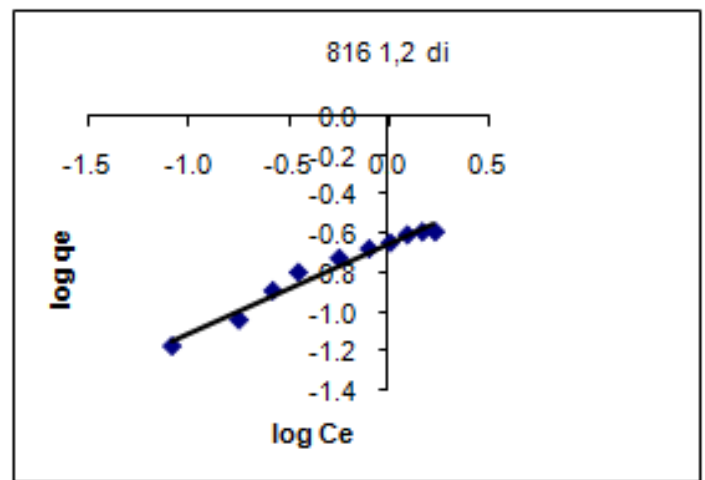

Fig.6.Freundlich adsorption isotherm System: F-816-1,2 Dihydroxybenzene - $\mathrm{Co}^{2+}$

The plot of $1 / \mathrm{q}_{\mathrm{e}}$ versus $1 / \mathrm{C}_{\mathrm{e}}$ helped in determination of $\mathrm{Q}^{\circ}$ from which the surface area occupied by cobalt ion on GAC can be determined. The surface area of the carbon through such Cobalt adsorption can then be represented as

$S^{\prime}=N a \cdot Q^{o} \cdot A$

Where,

$\mathrm{S}=$ Surface area of adsorbent, $\mathrm{cm}^{2} / \mathrm{g}$,

$\mathrm{Na}=$ Avogadro number and

$\mathrm{A}=$ Cross-sectional area of the adsorbent molecule, $\mathrm{cm}^{2}$.

It is possible to determine the surface area of the adsorbent using the technique of adsorbing Cobalt on ligand loaded GAC at the saturation level when a monolayer of the Cobalt would over the entire surface of the adsorbent. Determination of value of S' needed the determination of A the surface area occupied by a single Cobalt ion. The values of A were calculated using the expression given by Brunauer and Emmet.

$$
\mathrm{A}=4 \times 0.866\left[\frac{\mathrm{M}}{4 \sqrt{2} \cdot \mathrm{Na} \cdot \mathrm{d}}\right]^{2 / 3}
$$

Where,

$\mathrm{M} \quad=\quad$ Atomic weight of the Cobalt

$\mathrm{Na}=$ The Avogadro number

$\mathrm{d}=$ The density of the Cobalt, [15]

The values of $\mathrm{S}$ obtained from $\mathrm{q}_{\mathrm{e} \text { max }}$ are found to be fairly comparable with $\mathrm{S}^{\prime}$ (obtained from $\mathrm{Q}^{\circ}$ ) which are reported in Table 1

Table 1 Values of $\mathrm{Q}^{\mathrm{O}}, \mathrm{A}, \mathrm{S}$ and $\mathrm{S}^{\prime}$ for a system GAC-1,2 Dihydroxybenzene $-\mathrm{Co}^{2+}$

\begin{tabular}{|l|l|l|l|l|l|l|}
\hline Sr. No. & System & $\mathrm{Q}^{0}$ & $\begin{array}{l}\mathrm{A} \\
\left(\mathrm{cm}^{2}\right)\end{array}$ & $\begin{array}{l}\mathrm{S} \\
\left(\mathrm{cm}^{2} / \mathrm{gm}\right)\end{array}$ & $\begin{array}{l}S^{\prime} \\
\left(\mathrm{cm}^{2} / \mathrm{gm}\right)\end{array}$ & $\begin{array}{l}\mathrm{q}_{\text {emax }} \\
(\mathrm{mg} / \mathrm{m} . \mathrm{mol} .)\end{array}$ \\
\hline 1 & $\begin{array}{l}\text { F-100-1,2- } \\
\text { Dihydroxybenzene-Co }\end{array}$ & 0.2579 & $5.4225 \times 10^{-16}$ & $0.5048 \times 10^{3}$ & $0.5717 \times 10^{3}$ & 0.2277 \\
\hline 2 & $\begin{array}{l}\text { F-816-1,2- } \\
\text { Dihydroxybenzene -Co } \mathrm{Co}^{2+}\end{array}$ & 0.2802 & $5.4225 \times 10^{-16}$ & $0.5680 \times 10^{3}$ & $0.6212 \times 10^{3}$ & 0.2562 \\
\hline
\end{tabular}


Table 2 : Equations and regression analysis data

\begin{tabular}{|l|l|l|l|l|}
\hline System & Langmuir equation & $\begin{array}{l}\text { Regression } \\
\text { coefficient }\end{array}$ & $\begin{array}{l}\text { Freundlich } \\
\text { Equation }\end{array}$ & $\begin{array}{l}\text { Regression } \\
\text { Coefficient }\end{array}$ \\
\hline $\begin{array}{l}\text { F-100-1,2- } \\
\text { Dihydroxybenzene }-\mathrm{Co}^{2+}\end{array}$ & $\mathrm{Y}=1.203 \mathrm{x}+3.877$ & $\mathrm{R}^{2}=0.955$ & $\mathrm{Y}=0.458 \mathrm{x}-0.701$ & $\mathrm{R}^{2}=0.948$ \\
\hline $\begin{array}{l}\mathrm{F}-816-1,2- \\
\text { Dihydroxybenzene-Co }\end{array}$ & $\mathrm{Y}=1.002 \mathrm{X}+3.569$ & $\mathrm{R}^{2}=0.964$ & $\mathrm{Y}=0.456 \mathrm{x}-0.649$ & $\mathrm{R}^{2}=0.969$ \\
\hline
\end{tabular}

\section{Conclusion}

GAC was successfully used for the removal of cobalt from aqueous solution. It can be concluded that 1,2Dihydroxybenzene is a promising complexing agent for the removal of cobalt from aqueous solution. In this study, results showed that the adsorption of cobalt ion performed by GAC was very encouraging. The experimental data seen to be of the favourable type and were then subjected for adherence to both Langmuir and Freundlich adsorption isotherm. All adsorption isotherms of the Cobalt ion on different grades of carbons in combination with 1,2-Dihydroxybenzene clearly shows that F-816 adsorbs Cobalt ion to a greater extent as compared to F-100. This is probably due to availability of large active sites on the surface of GAC.

\section{Acknowledgement}

We express our sense of gratitude and thanks to the Director, Laxminarayan Institute of Technology, Nagpur and Principal, Shri. Shivaji Science College Congress Nagar, Nagpur for providing laboratory facilities to carry out the experimental work.

\section{References}

[1]. Ross S. M., Toxic metals in soil plant system, john Wiley and Son, chichester, 3-26 (1994)

[2]. Mukharjee A.G., 'Envirinmental pollution and health hazards; causes and control', in: S. Galgotia (Ed.), New Delhi, 1986, 1, 58.

[3]. Dara S.S., 'A Text Book of environmental chemistry and pollution control', in: S.Chand and Company Ltd (Ed.), New Delhi, 2002, 215 .

[4]. Taxicological Profile for cobalt U. S. Department of Health and Human services, Public Health Service, Agency for Toxic substances and Desease Registry.

[5]. Rivera-Utrilla, M. A. Fero-Garcia., Study of cobalt adsorption from aqueous solution on activated carbon from almond shells, Carbon, Vol 25, 1987, pp. 645-652.

[6]. Khope R.U., Halmare S.S., Natarajan G.S., Asian Journal of Chemistry, 2004,16,1716.

[7]. M. Ozacar I. A. Sengil and h. Turkmenler. Chem.. Eng. J. 143, 32 (2008).

[8]. Meshram Yogita K., Khope, R. U., Khati N. T., Batch adsorption studies for the removal of $\mathrm{Mn}^{2+}$ from aqueous solution, International Journal of Environmental Research and Development, Vol. 8(3A), 2014, pp.645-650.

[9]. Ho Y.S., International Journal of Environment and Pollution, 2008, 33, 1-13.

[10]. Gawande N.J., Chaudhari A.R. and Khope R.U., Advances in Applied Science Research, 2012, 3 (3):1836-1841.

[11]. Molting S., Dutta A. and Mukherjee S. N.,Application of adsorption process for treatment of landfill lechate, J. Environ. Res. Develop., 8(2),365-370, (2013).

[12]. Gunjate Jitendra K.*, Gholse Suresh B.1 and Khope Ramdas U.2, Adsorption studies of cobalt ions on surface modified granular activated carbon, Journal of Environmental Research And Development, 2014, Vol. 9 No. 02., $293-297$.

[13]. Taffarel S. R. and Jorge R., On the removal of $\mathrm{Mn}^{2+}$ ions by adsorption onto natural and activated Chilean zeolites, Mine. Engin., 22(2), 336-343, (2009).

[14]. Vogel A.I., Quantitative inorganic analysis, 4th Edn, Longman Group Ltd., England, 1978, 739.

[15]. Upadhyaya K. N., Textbook of Inorganic Chemistry, $2^{\text {nd }}$ Edn (Vikas Publishing House) New Delhi, $1994,727$. 